\title{
СИСТЕМА ВНУТРЕННЕГО ФИНАНСОВОГО КОНТРОЛЯ И ЕЕ ВОЗМОЖНОСТИ КОНТРОЛЯ ФИНАНСОВЫХ НАРУШЕНИЙ В ПРОЦЕССЕ РАСХОДОВАНИЯ СРЕДСТВ НА ФЕДЕРАЛЬНЫЕ ПРОЕКТЫ *
}

\author{
(c) 2020 Петров Александр Михайлович \\ доктор экономических наук, профессор департамента бизнес-аналитики \\ Финансовый университет при Правительстве РФ, Россия, Москва \\ E-mail:AMPetrov@fa.ru \\ (c) 2020 Никифорова Елена Владимировна \\ доктор экономических наук, профессор департамента бизнес-аналитики \\ Финансовый университет при Правительстве РФ, Россия, Москва \\ E-mail:EVNikiforova@fa.ru \\ (c) 2020 Шнайдер Ольга Владимировна \\ кандидат экономических наук, доцент департамента бизнес-аналитики \\ Финансовый университет при Правительстве РФ, Россия, Москва \\ E-mail: OVSHnajder@fa.ru
}

В настоящее время перед государством встает широкий спектр задач в части обеспечения достойного уровня жизни населения и улучшения его благосостояния. Для достижения обозначенных задач государство реализует федеральные проекты, которые финансируются из бюджетных средств. В свою очередь, успешная реализация федеральных проектов возможна при внедрении эффективной системы контроля в целом и внутри финансового контроля в частности.

В рамках новой экономической парадигмы элементы контроля расходования бюджетных средств могут оказаться неэффективными и устаревшими, что обуславливает необходимость их доработки по требованиям настоящего времени и подтверждает актуальность тем проведенного исследования. Проблема требует систематизированного детального анализа движения и направления финансовых средств, так как при нецелесообразном их использовании возрастает риск того, что государство может лишиться значительных ресурсов, и не достигнет поставленных целей.

Внутренний контроль, как особая функция управления субъекта хозяйствования, должен быть реализован на всех уровнях финансового управления. В свою очередь, система внутреннего финансового контроля в совокупности с законодательной базой в сфере бюджетных средств, кроме фиксирования правонарушений и отклонений от плана расходования, должна быть ориентирована на обоснование выводов о природе нарушений, направлений более рационального использования и предупреждения нецелевого назначения средств.

Регламент деятельности, управление субъектом хозяйствования, деятельность структурных подразделений и работу должностных лиц необходимо контролировать посредством общего внутреннего финансового контроля. Внутренний финансовый контроль по праву является важным инструментарием оценки правомерности деятельности не только на микроуровне, т.е. уровне субъектов хозяйствования и их рисков, а также инструментом оценки эффективности реализации государственных проектов.

В статье исследуются актуальные вопросы анализа и оценки системы внутреннего финансового контроля и ее возможности контроля финансовых нарушений в процессе расходования средств на федеральные проекты.

Ключевые слова: возможности, внутренний контроль, нарушения, процесс, система, федеральные проекты, финансы.

\footnotetext{
* Исследование выполнено в рамках научного проекта ГПХ ВТК-ГЗ-ПИ-15-20 «Создание системы внутреннего финансового контроля, обладающей возможностями для работы на опережающее устранение предпосылок финансовых нарушений при расходовании средств на федеральные проекты на основе оценки отраслевых рисков»
} 
Дифференциация расходов государственного бюджета на Государственные программы и национальные проекты обуславливает целевые индикаторы документов схожих Государственных программ и национальных проектов. Так, например, во многом совпадают данные для аналитики в части показателей Государственной программы «Развитие здравоохранения» и национальном проекте «Здравоохранение», а именно: смертность населения от всех причин; младенческая смертность; смертность от болезней системы кровообращения; смертность от дорожно-транспортных происшествий; смертность от новообразований (в том числе, злокачественных). Отличительной особенностью обозначенных проектов является несоответствие их сроков завершения (как правило, Государственные программы реализуются до 2020 года, а национальные проекты до 2024 года).

Однако средства, выделяемые на исполнение Государственных программ, входят в состав национальных проектов. Такой парадокс усложняет бюджетный процесс, увеличивая при этом документооборот и удорожание бюджетного контроля. С другой стороны, трудности реализации контроля за исполнением национальных проектов и формирования индикаторов могут вызвать непрозрачные и двусмысленные формулировки мероприятий, реализуемых в рамках национальных программ.

Выделим две ключевые причины, обуславливающие невозможность реализации результативного контроля за расходованием бюджетных средств (см. рисунок 1) [5, С. 169-178.].

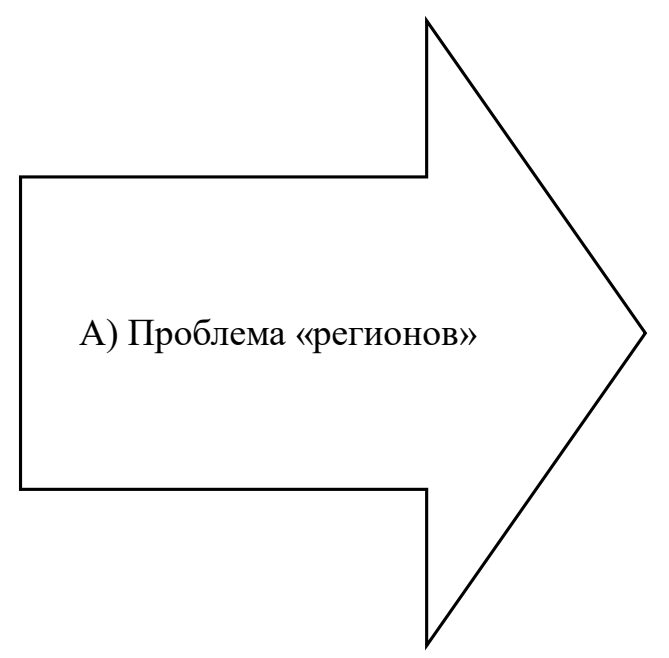

В России составлен достаточно существенный список проблем в части функционирования общей законодательной модели и подходов к осуществлению финансового контроля, включающего в себя как внутренний, так и внешний финансовый контроль муниципальных и федеральных уровней.

Первостепенной целью для государственного контроля является соблюдение законности через создание и полное исполнение четкой нормативной базы, регламентирующей работу и осуществление финансового контроля. Предметом государственного контроля выступят:

- нормативные акты, регламентирующие контрольную деятельность, ее подготовку и осуществление;

- прикладные программы, выступающие в качестве автоматизированных контрольных единиц;

- ведомственный перечень нарушений, отражающий качество выполнения государственных функций.

Проведение системного финансового контроля на государственном уровне является одними из преимущественных задач современной бюджетной политики Российской Федерации, в которой контрольные мероприятия должны соответствовать международным и европейским стандартам финансового контроля.

Внутренний финансовый контроль (далее ВФК), являясь универсальной функцией управления, способствует получению данных вариативности влияния различных факторов на изменение уровня эффективности реализации

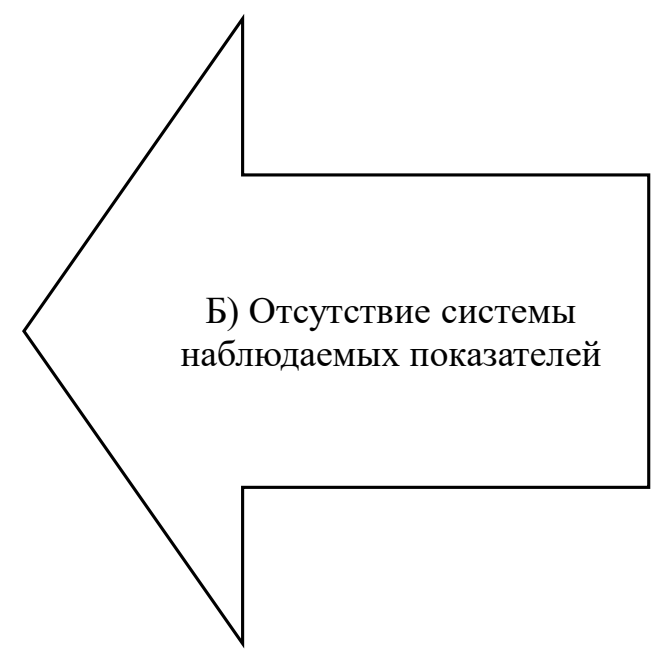

Рисунок 1. Причины, обуславливающие невозможность реализации результативного контроля за расходованием бюджетных средств 
проектов (мероприятий). Инструментарий ВФК многообразен и многогранен, что в свою очередь способствует подбору эффективной концепции его исполнения.

«Внутренний финансовый контроль государственных и муниципальных субъектов можно разделить на основные направления: внутренний финансовый контроль, внутренний аудит, управление рисками» [4, С. 113-119].

«Важно отметить факт того, что в современных экономических реалиях внутреннего финансового контроля должен быть включен и детально рассмотрен антикоррупционный аспект, анализ которого увеличит эффективность расходования средств и повысит общую исполнительность должностных и ответственных лиц» [5, С. 169-178].

«Внутренний контроль - одна из основных функций управления, представляющая собой систему постоянного мониторинга и проверки хозяйственной деятельности субъектов хозяйствования, необходимая для оценки правильности и эффективности принятых управленческих решений, выявления отклонений и своевременного их устранения, снижения рисков деятельности и управлению обусловленными рисками» [3, С. 135-144].

Любого уровня контроль обеспечивается по средствам соблюдения его принципов. Принципы ВФК представлены в таблице 1 [2].

В системе управления организациями и учреждениями внутренний финансовый контроль считается центральным элементом в устойчивом развитии. Охватывая весь управленческий цикл, внутренний финансовый контроль должен способствовать подтверждению эффективного использования средств, выявлению рисковых «полей» деятельности, сохранению финансовой устойчивости субъекта хозяйствования в быстро меняющихся условиях. Основные проблемы ВФК представлены на рисунке 2.

В целом можно предположить, что эффективность внутреннего финансового контроля заключается в достижении поставленных целей и выполнении поставленных задач, а результативность - в проведении внутреннего финансового контроля с наименьшим количеством ресурсов, способствуя формированию добавленной стоимости для организаций государственного сектора.

В рамках разработки направлений по совершенствованию системы ВФК, направленной на опережающее устранение возможных финансовых нарушений в процессе реализации федеральных проектов, ВФК должен стать ключевым инструментом каждого бизнес-процесса экономического субъекта, реализуемым службой внутреннего контроля и обеспечивающего устранение нарушений.

Эффективная система ВФК предполагает формирование необходимой инфраструктуры, обеспечивающей эффективный внутренний финансовый контроль, а именно:

- процедуры контроля необходимо реализовать на всех уровнях управления, которые принимают участие в реализации федерального проекта;

- регулярность, обеспечивающих закон-

Таблица 1. Принципы ВФК

\begin{tabular}{|l|l|}
\hline \multicolumn{1}{|c|}{ Принцип } & \multicolumn{1}{c|}{ Содержание } \\
\hline \multicolumn{1}{|c|}{1} & \multicolumn{1}{|c|}{2} \\
\hline Принцип объективности & $\begin{array}{l}\text { при осуществлении деятельности по планированию и проведению проверок } \\
\text { должны быть исключены предвзятость, субъективизм и предрасположенность } \\
\text { контрольных органов в отношении объекта проверки }\end{array}$ \\
\hline Принцип законности & $\begin{array}{l}\text { контрольные органы должны неукоснительно соблюдать нормы и правила, } \\
\text { установленные законодательством }\end{array}$ \\
\hline Принцип гласности & $\begin{array}{l}\text { деятельность контрольных органов должна быть «открытой», а средства } \\
\text { массовой информации должны обеспечивать доступ граждан к информации, } \\
\text { содержащей результаты контрольно-ревизионной деятельности }\end{array}$ \\
\hline Принцип независимости & $\begin{array}{l}\text { органы контроль должны быть организационно, функционально, материаль- } \\
\text { но самостоятельны и независимы от государства или проверяемого субъекта } \\
\text { хозяйствования }\end{array}$ \\
\hline Принцип ответственности & $\begin{array}{l}\text { контрольные органы должны надлежащим образом выполнять возложенные } \\
\text { на них контрольные функции, не превышая своих полномочий и неся полную } \\
\text { дисциплинарную, экономическую и административную ответственность за } \\
\text { исполнение своих обязательств }\end{array}$ \\
\hline
\end{tabular}

Источник: составлено авторами по материалам [2] 


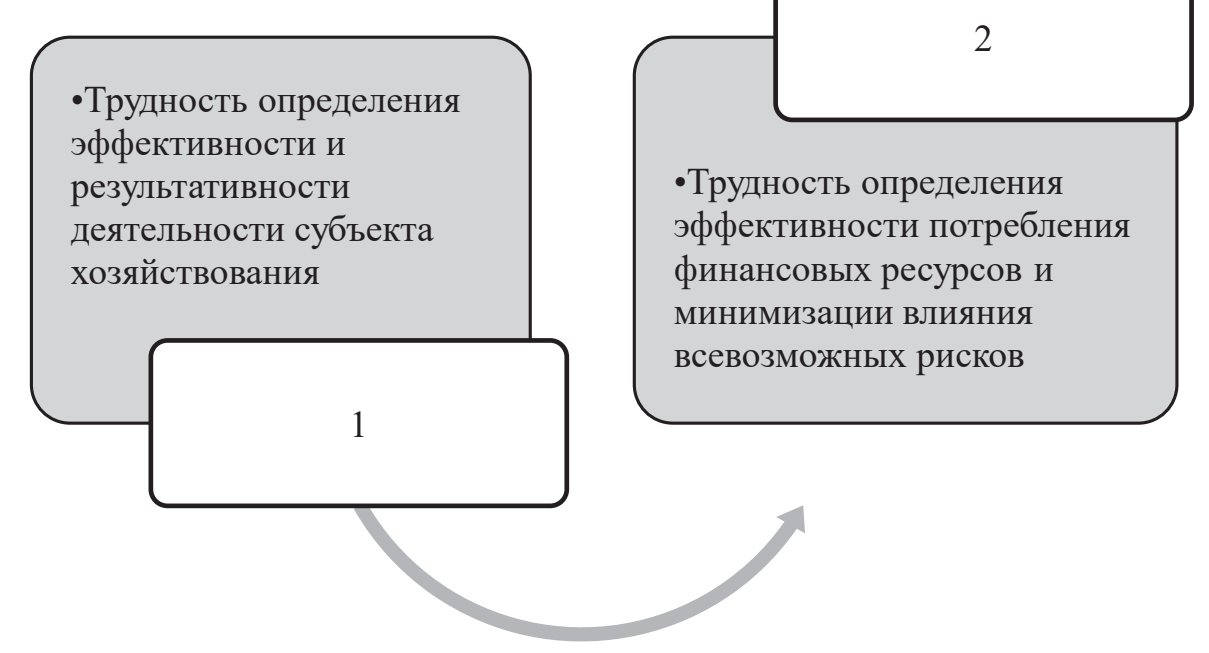

Рисунок 2. Основные проблемы внутреннего финансового контроля

ность операций по расходованию средств при выполнении федеральных проектов;

- разделение функционала и отсутствия конфликта интересов при выполнении федеральных проектов;

- возможность оценки объективности внешней информации о наличии и возможности влияния отраслевых рисков при выполнении федеральных проектов и расходовании по ним средств;

- оперативное доведение сведений до соответствующего персонала в рамках его компетенции при выполнении федеральных проектов;

- соответствие и безопасность информационных систем, баз данных, профессиональных программ, используемых при расходовании бюджетных средств, выделенных на федеральные проекты;

- своевременное доведение до высшего ру- ководства сведений о выявленных финансовых нарушениях.

В заключении отметим, что качественное построение методики системы внутреннего финансового контроля неотделимо от тщательного изучения нормативных и иных документов, регламентирующих организацию и функционирование ВФК, отечественных и зарубежных научных источников. Сложность и специфика процесса оценки требуют значительного различия между критериями оценки качества внутреннего финансового контроля и показателями для определения его качества. Общим для критериев и показателей является то, что они напрямую связаны с поставленными целями и задачами и ориентированы на контроль финансовых нарушений в процессе расходования средств на федеральные проекты.

\section{Библиографический список}

1. Завьялова, Л.В., Шилехин, К.Е.Внутренний финансовый контроль в условиях нового законодательства // Вестник Омского университета. Серия «Экономика».-2013.- № 4.- С. 88-99.

2. Кришталева, Т.И. Теория и методология взаимодействия контроля и налогообложения: монография / Т. И. Кришталева; Изд.-торговая корпорация «Дашков и К».- Москва: Дашков и Кㅇ 2008. - 309 с.

3. Мельник, М.В.Международные стандарты ISSAI и INTOSAI GOV, структура, содержание и практика применения высшими органами финансового контроля // Бухгалтерский учет, аудит и статистика. - 2012.№ 6.- C. 135-144.

4. Петров А. М., Бурцева К.Ю. К вопросу организации внутреннего финансового контроля в рамках расходования средств на федеральные проекты // Экономические науки. - 2020. - № 188. - С. 113-119.

5. Петров, А. М. Оперативный и превентивный инструментарий реализации внутреннего финансового контроля в рамках расходования средств на федеральные проекты // Экономические науки. -2020 . № 185. C. $169-178$. 